Original Article

\title{
CARDIOPROTECTIVE EFFICACY OF TAURINE ON LIPID-METABOLISM OF ISOPROTERENOL- INDUCED MYOCARDIAL INFARCTION
}

\author{
EMAN SALAH ABDEL-REHEIM* \\ *Zoology Department, Faculty of Science, Beni-Suef University, Beni-Suef, Egypt \\ Email: em4salah@yahoo.com
}

Received: 31 Aug 2016 Revised and Accepted: 05 0ct 2016

\begin{abstract}
Objective: The present study aimed to evaluate the effect of pre-treatment with taurine on rats in which MI had been induced using isoproterenol (ISO).

Methods: Rats were randomly allocated into three groups; the 1st group is the normal control (C) one, the 2nd is the isoproterenol cardiotoxic (ISO) one and the 3rd group is the taurine pretreated (T-ISO) one.

Results: The activities of the cardiac biomarker enzymes, AST, LDH, CK and CK-MB were elevated in the ISO-treated group. The membrane-bound $\mathrm{Na}^{+}-\mathrm{K}^{+}$and $\mathrm{Ca}^{2+}$ ATPase enzyme activities were decreased in the ISO-treated group. The lipid profile either in sera or cardiac tissues was increased in ISO-treated rats except for HDL-cholesterol and phospholipids. The cholesterol ester synthetase (CES) activity was elevated, while lecithin: Cholesterol acyltransferase (LCAT) and lipoprotein lipase (LPL) activities were decreased in the myocardial infarcted rats. In addition, the high level of the troponins I and T was an indication of cardiac necrosis. Pre-treatment with Taurine, however, ameliorated all of these changes, in addition to its effect in improving the oxidation process, as measured by lipid peroxidation and the antioxidant enzymes, superoxide dismutase and peroxidase enzymes.
\end{abstract}

Conclusion: Taurine showed amelioration effects on the changes in lipid profile, oxidative stress and myocardial infarction biomarkers and therefore, can be protected against cardiotoxicity.

Keywords: Taurine, isoproterenol (ISO), Cardiac biomarker enzymes, Lipid profile, Antioxidant defense system, Myocardial infarction.

(C) 2016 The Authors. Published by Innovare Academic Sciences Pvt Ltd. This is an open access article under the CC BY license (http://creativecommons.org/licenses/by/4. 0/) DOI: http://dx.doi.org/10.22159/ijpps.2016v8i12.14966

\section{INTRODUCTION}

Cardiovascular disease (CVD) remains the main cause of death in both developed and developing countries. Studies have shown that high levels of total cholesterol (TC), triglycerides (TG), low-density lipoprotein (LDL) cholesterol and apolipoproteins A-I, and low levels of high-density lipoprotein (HDL) cholesterol are the risk factors of CVD [1]. Of the many well-known model's isoproterenol (ISO)-induced myocardial necrosis, this rat model has often been used to evaluate several cardiac dysfunctions. ISO causes stress in the myocardium and a severe increase in the levels of serum and myocardial lipids, and also increases the level of LDL cholesterol in the blood, which in turn leads to coronary heart disease [2]. A number of patho-physiogenic mechanisms have been outlined to explain the lesions produced by ISO in experiments. Peroxidation of endogenous lipids has been shown to be a major factor in the cardiotoxic action of isoproterenol. Reactive oxygen species may contribute to atherogenesis and lead to the progression of atherogenic lesions by promoting oxidation of LDL [3].

Impairment of contractility during myocardial injury is primarily associated with deregulation of intracellular Ca2+homeostasis which plays an important role in mediating myocardial injury [4]. A marked increase in cytosolic free calcium $([\mathrm{Ca} 2+] \mathrm{i})$ has been reported in myocardial ischemic injury, and the occurrence of intracellular Ca2+overload has been suggested to lead to arrhythmias, contractile failure and ultimately cell death [5]. Cardiac troponins (cTn) have become well-known gold-standard blood biomarkers with high sensitivity and specificity for myocardial degeneration [6]. These contractile proteins are released from the myocardium in proportion to the degree of tissue injury and disruption of myocytes. The Tn regulatory complex binds to the thin, actin myofilament via tropomyosin (TnT) and mediates both calcium activation ( $\mathrm{TnC}$ ) and inhibition (TnI) of the ability of thick and thin myofilaments to slide to produce contraction. There are cardiac and skeletal muscle-specific forms of $\mathrm{TnI}$ and $\mathrm{TnT}$, although not for $\mathrm{TnC}$ [7]. There is growing evidence to suggest that increases in the serum concentration of cTn may be more sensitive than histologic analysis and other objective measures of cardiac myocyte injury [8].

Taurine (2-aminoethanesulfonic acid) is a conditionally-essential amino acid which is not utilized in protein synthesis, but rather is found free or in simple peptides. First discovered as a component of ox bile in 1827, Raiha [9] revealed that it was significant in human nutrition [10]. Several studies have shown that taurine is more essential in certain aspects of mammalian development, and have demonstrated that low levels of taurine are associated with various pathological lesions, including cardiomyopathy [11], retinal degeneration and growth retardation, especially if deficiency occurs during development [12]. It is also stabilised cell membranes [13] and acts as an antioxidant [14]. Derived from methionine and cysteine metabolism, taurine is known to play an important role in numerous physiological functions. While conjugation of bile acids is perhaps its best-known function, this accounts for only a small proportion of the total body pool of taurine in humans. Other metabolic actions of taurine include detoxification, membrane stabilization, osmoregulation, and modulation of cellular calcium levels. Clinically, taurine has been used in the treatment of a wide variety of conditions, including cardiovascular diseases, epilepsy and other seizure disorders, macular degeneration, Alzheimer's disease, hypertension, hepatic disorders, cystic fibrosis and diabetes [15-19]. The current study was an attempt to demonstrate that the hypolipidaemic and membrane stabilizing effects of taurine, in addition to its advantage as a natural antioxidant amino acid, allow it to play a role as a prophylactic agent in respect to myocardial infarction.

\section{MATERIALS AND METHODS}

Animal modeling and experimental design

White male albino rats (Rattus norvegicus), weighing 120-150g were used. They were obtained from the animal house of Helwan town, Cairo, Egypt. Animals were housed individually in polypropylene cages under standard conditions $\left(22^{\circ} \mathrm{C}\right)$ receiving rat 
pellet diet and water ad libitum. They were acclimatized under standard laboratory conditions of temperature and humidity with a normal photoperiod (12 h light: dark cycle) for seven days. All animal experiments were performed in accordance with guidelines for the Care and Use of Laboratory Animals that approved by the animal Ethics Committee at Beni-Sueif University.

Rats were randomly allocated into three groups $(n=8)$. The first and second ones are intubated for two weeks with normal phosphate buffer saline (PH 7.4). The third one treated daily with taurine dissolved in normal saline (100 mg/kg bwt.) for two weeks by gastric intubation. After dose and previous preliminary studies; $70 \mathrm{mg} / \mathrm{kg}$ body weight isoproterenol for two consecutive days is the most effective inducible dose [20]. So, at the last two days of the experiment, the 2nd and 3rd groups were injected subcutaneously with $70 \mathrm{mg} / \mathrm{kg}$ body weight isoproterenol for two consecutive days. The 1st group is the normal control (C) one; the 2nd is the isoproterenol cardiotoxic (ISO) one and the 3rd group is the taurine pretreated (T-ISO) one. All groups are decapitated after the two days of isoproterenol injection [20].

\section{Tissue homogenate preparation}

At the end of the experimental period, heart from control and experimental groups were excised and washed with ice-cold saline $(\mathrm{NaCl} 0.9 \%)$ to remove blood. The heart was weighed for calculating relative heart weight. For the biochemical estimations, the ventricular heart tissues were homogenized in ice-cold saline using Teflon homogenizer, and centrifuged; the supernatants were separated and used for the biochemical and oxidative stress estimations.

\section{Estimation of serum markers}

Sera from each group were frozen and stored at-20 ${ }^{\circ}$ until biochemical determination. Cardiac enzymes biomarkers; aspartate transaminase (AST) activity was determined according to the kinetic method of Schumann and Klauke [21], Lactate dehydrogenase (LDH) activity was determined according to method of Young [22], Creatine phosphokinase (CK) activities were determined by the method of Okinaka [23], Creatine phosphokinase of M-type (CK-MB) activity was determined according to method of Young [24].

Triglycerides concentration was determined according to the method of Buccolo and David [25]; Total cholesterol was estimated according to the method of Allian et al. [26]; phospholipids were determined according to the method of Connerty [27] and the method described by Boden et al. [28], was followed for the estimation of free fatty acids. Lipoproteins were also determined; HDL-cholesterol concentration was measured according to the method of Allain et al. [26], LDL-and VLDL-cholesterol concentration were determined according to Friendewald et al. [29] formula. Lipoprotein (a) was determined according to the method of Kamstrup et al. [30]. Cardiovascular risk (CVR) indices were calculated according to Hegele [31] formula and anti-atherogenic index (AAI) was determined according to Guido and Joseph, [32] formula. Troponin I (TPI) and troponin T (TPT) were determined using an enzyme-linked immunosorbent assay (ELISA) by the method of Bhaskar and Rao [33].

\section{Estimation of tissue markers}

Tissue homogenate measurements included triglycerides, total cholesterol, phospholipids and free fatty acids by the methods mentioned above. The activities of the lipid metabolizing enzymes such as cholesterol ester synthetase (CES), lecithin: Cholesterol acyltransferase (LCAT) and lipoprotein lipase (LPL) were determined in the heart sample as suggested by Kothari et al. [34], Hitz et al. [35] and Slater et al. [36] respectively. Activities of $\mathrm{Na}^{+} \mathrm{K}^{+}$ ATPase and $\mathrm{Ca}^{2+}$ ATPase in heart homogenate were estimated by the Swann and Steketee [37], and Ohnishi [38], respectively.

\section{Assessment of myocardial oxidative stress}

Myocardial lipid peroxides were measured according to the method of Preuss et al. [39] and the proteins content was determined by biuret method. Also, the myocardial antioxidant enzyme activities, superoxide dismutase (SOD) and peroxidase (POX) were determined according to the chemical method of Marklund and Marklund [40] and Kar and Mishra [41], respectively.

\section{Statistical analysis}

Analysis of Variance on SPSS software package (version 20) was used to test the present data. Data were expressed as mean \pm SE. Oneway analysis of variance (ANOVA) was used to study the significant differences. The level of significance was taken as $p<0.05$. In the case of significant difference, the Multiple Range Comparisons (Duncan's test) was selected from the post Hoc window on the same statistical package to detect the distinct variance between means.

\section{RESULTS}

\section{Effect of ISO on relative heart weight}

The changes in the relative heart weight in the experimental groups are illustrated in fig. 1, with the highest relative heart weight being in the isoproterenol (ISO) induced group (0.569), which was significantly elevated, compared to the control group (0.347). This elevation, however, decreased significantly $(0.447)$ in the prophylactic taurine group.

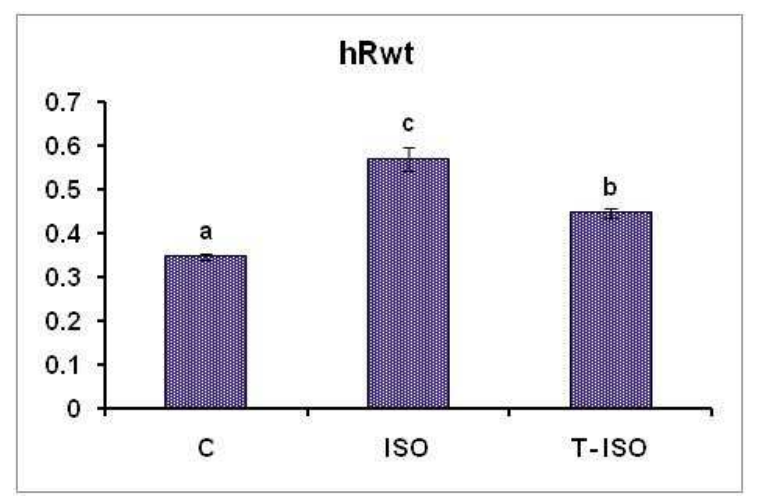

Fig. 1: Prophylactic effect of taurine on heart relative weight of isoproterenol cardiotoxic rats,-(c) Control, (iso) Isoproterenol, (T-iso) Taurine+Isoproterenol,-Data expressed as mean $\pm \mathrm{SE}$ for six rats/group,-Values with the same superscript letter are similar (non-significant, $P>0.05$ ) whereas others aren't (significant, $\mathrm{P}<0.05$ )

\section{Serum cardiotoxicity}

The serum cardiotoxicity was represented by the enzymatic biomarkers of cardiotoxicity (table 1). The ISO group increased significantly $(\mathrm{P}<0.001)$ for all the measured enzymes. Changes in the serum lipid profile, which are illustrated in table 2 , indicate a very highly significantly $(\mathrm{P}<0.001)$ increased level of triglycerides, cholesterol, and free fatty acids as compared to the control group. Phospholipids, meanwhile, were significantly $(\mathrm{P}<0.001)$ decreased in the ISO group compared to the control group. Changes in lipoproteins (LDL, vLDL, and lipoprotein A) followed the same pattern as that of the lipid profile, while HDL was significantly $(\mathrm{P}<0.001)$ decreased (table 3$)$. The cardiovascular risk factors were increased in the ISO group compared to the control one and ameliorated in T-ISO group (table 4). In respect to the antiatherogenic factor, the ISO group showed the lowest level, followed by T-ISO group than the control one. Regarding lipid metabolizing enzymes (fig. 2), cholesterol ester synthetase (CES) was significantly ameliorated in the T-ISO group in comparison to the ISO-group and control group of $3.910 \mathrm{nmol}$ esterified cholesterol/100g tissue. In respect to lecithin, meanwhile, cholesterol acyltransferase (LCAT) and lipoprotein lipase (LPL) were decreased significantly in the ISOinduced cardiotoxic group compared to measurements of 18.80 nmol esterified cholesterol/100g tissue and 12.667 nmol FFA liberated $/ 100 \mathrm{~g}$ tissue in the taurine-treated group. The control group, in contrast, exhibited $24.60 \mathrm{nmol}$ esterified cholesterol $/ 100 \mathrm{~g}$ tissue and $18.433 \mathrm{nmol}$ FFA liberated/100g tissue. The muscle troponin types I and $\mathrm{T}$ illustrated in fig. 3, showed a significant $(\mathrm{P}<0.001)$ increase in the ISO group compared to the control group but increased to a lesser extent in the taurine protected group. 
Table 1: Prophylactic effect of taurine on serum cardiotoxic biomarkers enzymes in cardiotoxic rats

\begin{tabular}{llll}
\hline Groups & AST (IU/l) & LDH (IU/l) & CK (IU/I) \\
\hline Control & $64.167 \pm 4.757^{\mathrm{a}}$ & $157.833 \pm 14.845^{\mathrm{a}}$ & $154.338 \pm 19.116^{\mathrm{a}}$ \\
Isoproterenol & $138.667 \pm 2.871^{\mathrm{c}}$ & $725.000 \pm 39.569^{\mathrm{c}}$ & $469.667 \pm 17.761^{\mathrm{c}}$ \\
Taurine+Isoproterenol & $97.417 \pm 2.922^{\mathrm{b}}$ & $426.500 \pm 27.956^{\mathrm{b}}$ & $259.500 \pm 22.803^{\mathrm{b}}$ \\
\hline
\end{tabular}

-Data expressed as mean \pm SE for six rats/group, -Values with the same superscript letter are non-significantly different $(\mathrm{P}>0.05)$.

Table 2: Prophylactic effect of taurine on serum lipid profile in cardiotoxic rats

\begin{tabular}{llll}
\hline Groups & Tg (mg/d) & TCh (mg/dl) & PL (mg/dl) \\
\hline Control & $84.100 \pm 3.511^{\mathrm{a}}$ & $86.000 \pm 3.502^{\mathrm{a}}$ & $118.400 \pm 6.089^{\mathrm{c}}$ \\
Isoproterenol & $176.167 \pm 5.282^{\mathrm{c}}$ & $149.500 \pm 4.311^{\mathrm{c}}$ & $62.467 \pm 4.980^{\mathrm{a}}$ \\
Taurine+Isoproterenol & $125.667 \pm 5.451^{\mathrm{b}}$ & $114.300 \pm 3.222^{\mathrm{b}}$ & $94.687 \pm 5.515^{\mathrm{b}}$ \\
\hline
\end{tabular}

-Data expressed as mean \pm SE for six rats/group, -Values with the same superscript letter are non-significantly different (P>0.05).

Table 3: Prophylactic effect of taurine on serum lipoproteins level in cardiotoxic rats

\begin{tabular}{|c|c|c|c|c|}
\hline Groups & HDL-Ch (mg/dl) & LDL-Ch (mg/dl) & vLDL-Ch (mg/dl) & Lipoprotein-A (mg/dl) \\
\hline Control & $64.833 \pm 3.628^{c}$ & $37.667 \pm 0.919^{a}$ & $17.217 \pm 0.594^{\mathrm{a}}$ & $22.200 \pm 1.303^{\mathrm{a}}$ \\
\hline Isoproterenol & $37.833 \pm 2.088^{a}$ & $79.000 \pm 2.852^{\mathrm{c}}$ & $31.517 \pm 1.130^{c}$ & $42.290 \pm 1.327^{c}$ \\
\hline Taurine+Isoproterenol & $53.333 \pm 1.542^{\mathrm{b}}$ & $57.667 \pm 3.148^{b}$ & $23.267 \pm 0.617^{b}$ & $28.367 \pm 0.911^{b}$ \\
\hline
\end{tabular}

-Data expressed as mean \pm SE for six rats/group, -Values with the same superscript letter are non-significantly different (P>0.05).

Table 4: Prophylactic effect of taurine on cardiovascular risk and anti-atherogenic factors in cardiotoxic rats

\begin{tabular}{lllll}
\hline Groups & R1 (TCh/HDL) & R2 (LDL/HDL) & R3 (Tg/HDL) & Anti-atherogenic, (HDLx100 TCh-HDL) \\
\hline Control & $1.345 \pm 0.078^{\mathrm{a}}$ & $0.587 \pm 0.034^{\mathrm{a}}$ & $1.313 \pm 0.079^{\mathrm{a}}$ & $355.763 \pm 41.183^{\mathrm{b}}$ \\
Isoproterenol & $3.783 \pm 0.362^{\mathrm{c}}$ & $2.135 \pm 0.174^{\mathrm{c}}$ & $4.385 \pm 0.183^{\mathrm{c}}$ & $43.498 \pm 2.996^{\mathrm{a}}$ \\
Taurine+Isoproterenol & $2.150 \pm 0.059^{\mathrm{b}}$ & $1.083 \pm 0.054^{\mathrm{b}}$ & $2.358 \pm 0.082^{\mathrm{b}}$ & $91.167 \pm 4.175^{\mathrm{a}}$ \\
\hline
\end{tabular}

-Data expressed as mean \pm SE for six rats/group, -Values with the same superscript letter are non-significantly different (P>0.05).

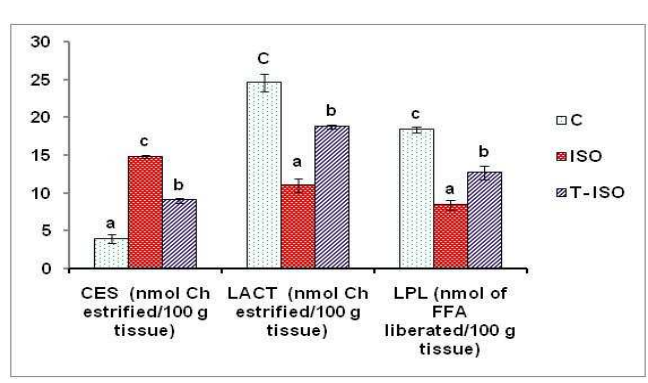

Fig. 2: Prophylactic effect of taurine on lipid metabolizing enzymes of isoproterenol cardiotoxic rats, Data expressed as mean $\pm S E$ for six rats/group, -Values with the same superscript letter are similar (non-significant, $P>0.05$ ) whereas others aren't (significant, $P<0.05$ )

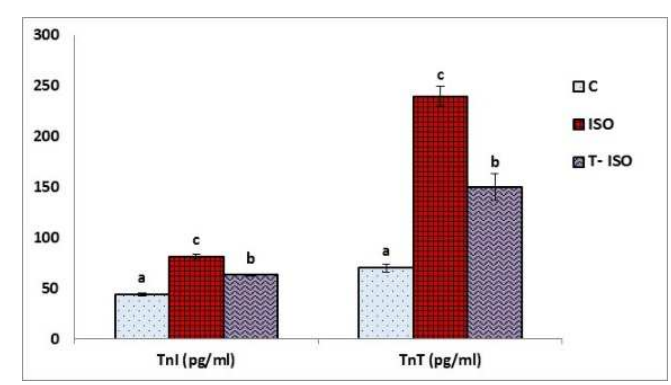

Fig. 3: Prophylactic effect of taurine on troponin I and troponin $T$ in the serum of isoproterenol cardiotoxic rats. Data expressed as mean $\pm S E$ for six rats/group. Values with the same superscript letter are similar (non-significant, $P>0.05$ ) whereas others aren't (significant, $P<0.05$ ).

\section{Tissue cardiotoxicity}

Fig. 4 showed that ISO induction led to a significant $(\mathrm{P}<0.001)$ decrease in the protein content in comparison to the control group in the heart tissue while pre-treatment with taurine served to maintain the protein content from the high decrement in the heart tissue. The membrane ATPase bound enzyme activities (Na+-K+and $\mathrm{Ca} 2+\mathrm{ATPase})$ are illustrated in fig. 5, which demonstrates that they showed the same behavioral activities. $\mathrm{Na}^{+}-\mathrm{K}^{+}$ATPase recorded the highest activity in the control group followed by the taurine pre-treatment group then the ISO-treated group. Also, Ca2+ATPase recorded the highest activity in the control group followed by the taurine pre-treatment group then the ISO-treated one. Table 6 indicate the ameliorative effect of taurine on the lipid content in the heart tissue, as all the increased cholesterol, triglycerides, free fatty acids contents after isoproterenol injection decreased with taurine treatment while it reincreased the decreased phospholipids. The oxidation process was evaluated by the lipid peroxidation process and two antioxidant enzymes (fig. 6). In comparison to the control group, lipid peroxidation was significantly elevated $(\mathrm{P}<0.001)$ in the ISO cardio toxified group while the superoxide dismutase $(\mathrm{P}<0.01)$ and peroxidase $(\mathrm{P}<0.001)$ enzymes were significantly decreased. The taurine pre-treated group showed amelioration in the oxidation process with decreased lipid peroxidation and increased antioxidant enzymes.

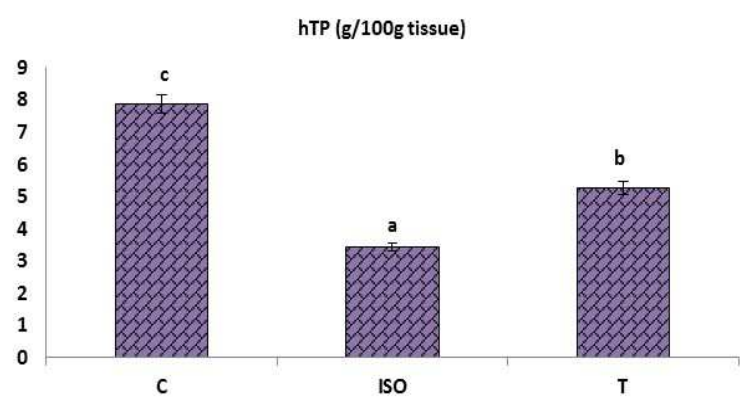

Fig. 4: Prophylactic effect of taurine on protein content in the heart tissue of isoproterenol cardiotoxic rats. Data expressed as mean $\pm S E$ for six rats/group. Values with the same superscript letter are similar (non-significant, $P>0.05$ ) whereas others aren't (significant, $P<0.05$ ). 


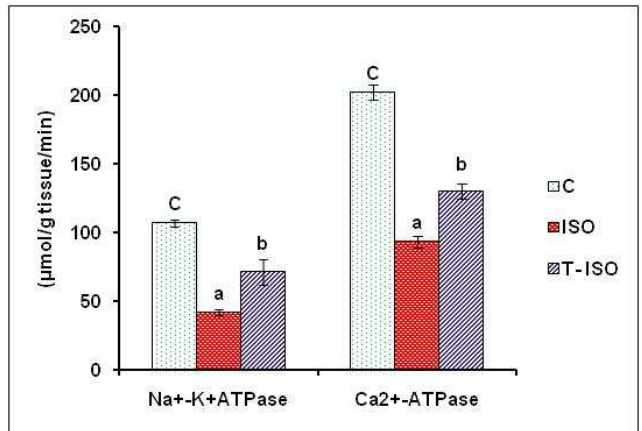

Fig. 5: Prophylactic effect of taurine on membrane-bound Na+$\mathrm{K}+\mathrm{ATPase}$ and Ca2+ATPase in the heart tissue of isoproterenol cardiotoxic rats, Data expressed as mean \pm SE for six rats/group,

Values with the same superscript letter are similar (nonsignificant, $P>0.05$ ) whereas others aren't (significant, $P<0.05$ )

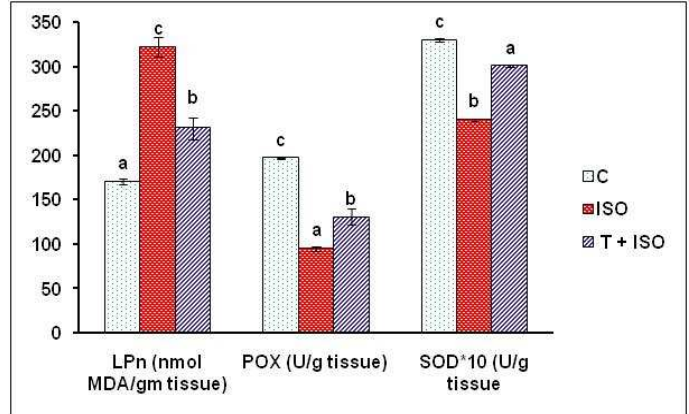

Fig. 6: Prophylactic effect of taurine on lipid peroxidation, superoxide dismutase, and peroxidase activities in the heart tissue of isoproterenol cardiotoxic rats, Data expressed as mean $\pm S E$ for six rats/group, Values with the same superscript letter are similar (non-significant, $P>0.05$ ) whereas others aren't (significant, $\mathrm{P}<0.05$ )

Table 5: Prophylactic effect of taurine on lipid profile level in the heart tissue of cardiotoxic rats

\begin{tabular}{|c|c|c|c|c|c|}
\hline Groups & $\mathrm{Tg}(\mathrm{mg} / \mathrm{dl})$ & TCh (mg/dl) & PL (mg/dl) & FFA (mg/dl) & $\mathrm{C} / \mathrm{P}$ ratio \\
\hline Control & $8.333 \pm 0.039^{a}$ & $10.453 \pm 0.094^{\mathrm{a}}$ & $34.667 \pm 0.558^{c}$ & $1.263 \pm 0.144^{a}$ & $0.294 \pm 0.004^{\mathrm{a}}$ \\
\hline Isoproterenol & $9.367 \pm 0.086^{c}$ & $12.320 \pm 0.105^{\mathrm{c}}$ & $16.500 \pm 0.847^{a}$ & $3.648 \pm 0.272^{c}$ & $0.738 \pm 0.028^{c}$ \\
\hline Taurine+Isoproterenol & $8.740 \pm 0.037^{b}$ & $11.333 \pm 0.037^{b}$ & $24.867 \pm 0.804^{b}$ & $2.491 \pm 0.159^{b}$ & $0.469 \pm 0.029^{b}$ \\
\hline
\end{tabular}

-Data expressed as mean \pm SE for six rats/group, -Values with the same superscript letter are non-significantly different (P>0.05).

\section{DISCUSSION}

This study tested the use of taurine as a natural antioxidant agent affecting the myocardial cells and serving to protect the heart from infarction. To evaluate its cardioprotective efficacy, several parameters were checked. Firstly isoproterenol was used to induce the experimental model of myocardial infarction since this is considered a standard model to study the beneficial effects of many drugs and cardiac functions [42]. Isoproterenol was observed in increasing the relative heart weight, which is in accordance with many previous studies showing cardiac hypertrophy [43-45]. It was also shown that isoproterenol leads to myocardial necrosis characterized by increased end-diastolic volume, end-diastolic pressure and left ventricular wall thickness. The cardiac hypertrophy after acute administration of isoproterenol is possibly also due to the accumulation of intramuscular water and the formation of interstitial fibrosis, especially at the subendocardial and apical cardiac levels, as well as invasion by inflammatory cells [46]. The formation of fibers and accumulation of intramuscular water explains the decrease in the protein content of cardiac tissue that was recorded in ISO-treated rats.

Taurine is a non-protein sulphur containing an amino acid that has been shown to play several essential roles in the human body [47]. It has been proved that taurine makes up more than $50 \%$ of the total free amino acid pool in the mammalian heart [48]. Earlier studies have demonstrated that pathology develops in the myocardium if the animal is depleted of taurine stores either through a taurine deficient diet or use of taurine transport antagonists [49]. This means that it is a principal constituent in and for the myocytes. Its effect on increased myocardial weight has been previously studied $[50,51]$, and it has been found to prevent the hypertrophy of the myocytes, possibly due to its osmoregulatory effect, avoiding myocyte swelling [52] and protecting their normal constituents from fibrosis.

The cardiotoxic parameters indicated an increase in AST, LDH, CK, CK-MB activities and a decrease in the membrane-bound $\mathrm{Na}+-\mathrm{K}+$ and Ca2+ATPase enzyme activities. The cardiac troponins ( $\mathrm{I}$ and $\mathrm{T}$ ) biomarkers increased in the serum of the myocardial infarcted rats. ISO induction also led to a disturbance in the oxidation process as lipid peroxidation increased and the antioxidant enzymes SOD and POX decreased. These results parallel those of many studies [42], [53-55]. Several mechanisms for the cardiotoxic effects of high levels of ISO have been suggested. These mechanisms include: 1) functional hypoxia and ischemia, 2) coronary insufficiency, 3) alterations in metabolism, 4) decreased the level of high-energy phosphate stores, 5) intracellular Ca2+overload, 6) changes in electrolyte contents and 7) oxidative stress. These changes are interpreted as complex entities [54]. These previous studies have also reported that oxidative stress is, probably, one of the main mechanisms through by which ISO exert its toxic effects. The oxidized products have the ability to interact with sulphydryl groups of various proteins and also lead to the production of superoxide anions and subsequently hydrogen peroxide. This results in changes in microsomal permeability, mitochondrial Ca2+uptake and a decrease in ATP production. This explains the decrease in ATPase activities which are also negatively affected by peroxidation of the membrane lipids and the formation of highly reactive hydroxyl radicals which cause protein, lipid and DNA damage [56]. These effects explained the increased MDA content and decreased antioxidant enzyme activities in the cardiac tissue of the ISOintoxicated group because superoxide radicals generated at the site of damage decrease their activities and the accumulation of superoxide anions itself damages the myocardium. This accounts for the elevation of serum activity of AST, LDH, CK and CK-MB and serum level of cTn-I and cTnT in the current experiment several hours after ISOadministration. Myocytes death or altered membrane permeability causes the cytosolic contents to eventually enter the systemic circulation, where they may be detected as markers of the ischemic heart disease.

The osmoregulatory activity of taurine appears to be an important determinant of cell survival [57]. Taurine is an amino acid that differs from the more familiar amino acids both in being a sulphonic rather than a carboxylic amino acid and in being a $\beta$ amino acid rather than an $\alpha$ amino acid. Its dipolar character may weaken charge dependent, protein-protein interactions and inhibit the forcegenerating myosin-actin interaction [58], decreasing myocytes activity, preserving energy and preventing cardiac hypoxia. This may explain the low level of the cardiac dysfunction biomarker enzymes, as it maintains the cells from death [57], and also elucidates the importance of taurine to the myocardial structure and contractile function, which agrees with the amelioration of the membrane-bound enzyme activities shown here. Taurine influences the activity of the sarcoplasmic reticular Ca2+ATPase through at least two factors. First, it enhances the phosphorylation of the sarcoplasmic reticular phosphoprotein, phospholamban [59]. 
Because the phosphorylation of phospholamban enhances the rate of $\mathrm{Ca} 2+$ uptake by the sarcoplasmic reticulum, it, therefore, increases the rate of myocardial relaxation [60]. Second, due to its antioxidant activity: according to Park et al. [61] the activity of the sarcoplasmic reticular $\mathrm{Ca}^{2+}$ ATPase is inhibited by oxidative stress as lipid peroxidation is increased. It is known that sarcoplasmic reticular $\mathrm{Ca} 2+$ uptake and release play key roles in regulating $\left[\mathrm{Ca}^{2+}\right]$ binding to troponin. It is not surprising; therefore, that taurine is required for normal systolic and diastolic function. The activation of the $\mathrm{Na}^{+}-$ $\mathrm{K}^{+}$ATPase by taurine may be explained by its role in spanning membrane bound protein known as phospholamban protein from a sensitive volume channel which was found that its decrement leads to the decrease in $\mathrm{Na}^{+}-\mathrm{K}^{+} \mathrm{ATPase}$ activity [62].

Taurine can interact with the natural phospholipids of the biological membranes and protect the membrane organization against free radical attack, restoring the activity of membrane-bound enzyme ATPase. It can also preserve the sulph-hydral 'SH' group and inhibit membrane lipid peroxidation and the consequent alterations in the activity of various ATPases [63]. By these means, and by preserving the energy in the cell, it maintains the ATPase activity, as indicated in the treated group. Preserving the energy, maintaining the phospholipid content in the membrane and regulating the ionic balance in the cell, it protects the myocytes from death and prevents cytosolic leakage, as indicated by the low enzyme activities and low Tns level in our treated group. Lipid metabolism plays an important role in myocardial necrosis produced by ischemia [64]. An excess of lipids in the circulation is considered to accelerate the development of arteriosclerosis. This experiment indicated a disruption in lipid parameters after ISO-induction, which is compatible with many previous studies [65-67].

In respect to the lipid metabolizing enzymes in the present study there was a significant decrease in cardiac LCAT and LPL activity but a significant increase in the activity of CES in ISO-intoxicated rats. HDL is the main substrate for LCAT for cholesterol esterification and incorporation $[68,69]$. An inverse correlation between TG and LPL activity has been reported. The hypertriglyceridemia observed in ISO-intoxicated rats is due to the decreased activity of LPL in the heart and decreased uptake of triglycerides from the circulation, which also leads to an elevated flux of fatty acids and impaired removal of very low-density lipoprotein (VLDL) from the serum [70]. The increase in the levels of FFA in ISO-intoxicated rats is due to the increased lipolysis of triglycerides from adipose tissue stores. This enters into the myocardium since the heart can utilize FFA for its energy requirements; the excess FFA may be used for the synthesis of TG, resulting in hypertriglyceridemia. Also, the, increased peroxidation of membrane phospholipids releases free fatty acids by the action of phospholipase A2, which is activated by $\mathrm{Ca}^{2+}$ ion accumulated in the cell [71]. The increased activity of CES in ISO-intoxicated rats results in the accumulation of ester cholesterol which in turn results in myocardial membrane damage $[72,73]$.

The significant increase observed in the lipid accumulation in cardiac tissue homogenate from the ISO group is in accordance with the results of other investigations $[74,75]$. These authors referred to the high lipid content enhanced lipid biosynthesis by cardiac cAMP, which is increased and reported as the primary causes of ISOinduced cardiotoxicity [75]. The changes in membrane cholesterol content affect its fluidity, permeability to ions, the activities of membrane-bound enzymes and increased degradation of phospholipids [74]. Accelerated phospholipid degradation with the increased ratio of cholesterol/phospholipids (C/P ratio) could produce membrane dysfunction, resulting in cell injury and ultimate cell death. Another option, with very promising results in the context of cardiovascular risk stratification and assessment of the effectiveness of lipid-lowering interventions, is the use of lipid ratios, which have the added advantage of being easy to use in clinical practice and the changes in these ratios are better indicators of cardiovascular disease risk than the absolute levels of individual lipids [76].

There are many studies showing the hypolipidemic effect of taurine in ISO-treated rats [77-79]. The oldest and best-documented function of taurine is its conjugation with bile acids in bile salt synthesis [80]. The hypolipidemic effect of taurine is partly due to the inhibition of cholesterol absorption in the intestine [81]. It also works by increasing the conversion of cholesterol to bile acid by enhancing 7- $\alpha$ hydroxylase, the rate-limiting enzyme of hepatic cholesterol catabolism, and conjoining with bile acids, this is indicated by enhanced mRNA expression and enzymatic activity of 7a-hydroxylase [82]. Murakami et al. [83] also showed that taurine induced lower cholesterol level in diabetic rats by increasing LDL-receptors, thereby mediating LDL turnover. It has also been suggested that taurine may be responsible for the increase of HDL, modifying cholesterol synthesis in the liver and/or balance of each of the serum lipoprotein fractions containing cholesterol [84]. Taurine is a hypocholesterolemic agent [85], possibly by enhancing LDL receptor binding in the liver [86]. The reduced levels of triglyceride following taurine treatment are explained by its LPL-lowering effect [87].

\section{CONCLUSION}

The finding of the current study clearly demonstrated that taurine significantly protected against the toxic effects of ISO via alleviating the altered cardiac biomarker enzymes which may be mediated by attenuate the oxidation mechanism system. In addition, hyperlipidemia and its cardiovascular complications were markedly ameliorated through increasing HDL level and enhancement of LDL turnover.

\section{ACKNOWLEDGMENT}

I would like to thank the staff of Zoology Department, Faculty of Science, Beni-Suef University.

\section{CONFLICT OF INTERESTS}

\section{Declared none}

\section{REFERENCES}

1. Glew RH, Kassam HA, Bhanji RA, Okorodudu A, VanderJagt DJ. Serum lipid profiles and risk of cardiovascular disease in three different male populations in northern Nigeria. J Health Popul Nutr 2002;20:166-74.

2. Nair PS, Devi CS. Efficacy of mangiferin on serum and heart tissue lipids in rats subjected to isoproterenol-induced cardiotoxicity. Toxicology 2006;228:135-9.

3. Benelli $R$, Venè $R$, Bisacchi $D$, Garbisa $S$, Albini A. Anti-invasive effects of green tea polyphenol epigallocatechin-3-gallate (EGCG), a natural inhibitor of metallo and serine proteases. Biol Chem 2002;383:101-5.

4. Valen G. Cellular signaling mechanisms in adaptation to ischemia-induced myocardial damage. Ann Med 2003;35:300-7.

5. Orrenius S, Zhivotovsky B, Nicotera P. Regulation of cell death: the calcium-apoptosis link. Nat Rev Mol Cell Biol 2003;4:552-65.

6. Antman EM. Decision-making with cardiac troponin tests. New England J Med 2002;346:2079-82.

7. Metzger JM, Westfall MV. Covalent and non-covalent modification of thin filament action the essential role of troponin in cardiac muscle regulation. Circ Res 2004;94:146-58.

8. Kurata M, Iidaka T, Sasayama Y, Fukushima T, Sakimura M. Correlation among clinicopathological parameters of myocardial damage in rats treated with isoproterenol. Exp Anim 2007;56:57-62.

9. Raiha N, Rassin D, Heinonen K, Gaull GE. Milk protein quality and quantity: Biochemical and growth effects in low birth weight infants (LBWI). Pediatr Res 1975;9:370.

10. Birdsall TC. Therapeutic applications of taurine. Alternative Med Rev 1998;3:128-36.

11. Ito T, Sw Fau-Azuma JS, Azuma J. The potential usefulness of taurine on diabetes mellitus and its complications. Amino Acids 2012;42:1529-39.

12. Lourenco R, Camilo M. Taurine: a conditionally essential amino acid in humans? An overview in health and disease. Nutr Hosp 2002;17:262-70.

13. Heller-Stilb B, van Roeyen C, Rascher K, Hartwig HG, Huth A, Seeliger MW, et al. Disruption of the taurine transporter gene (taut) leads to retinal degeneration in mice. FASEB J 2002;16:231-3.

14. Atmaca G. Antioxidant effects of sulfur-containing amino acids. Yonsei Med J 2004;45:776-8. 
15. Parcell S. Sulfur in human nutrition and applications in medicine. Alternative Med Rev 2002;7:22-44.

16. Lombardini JB, Militante JD. Effects of taurine supplementation on cholesterol levels with potential ramification in atherosclerosis. Adv Exp Med Biol 2006;583:251-4.

17. Allard ML, Jeejeebhoy KN, Sole MJ. The management of conditioned nutritional requirements in heart failure. Heart Failure Rev 2006;11:75-82.

18. El-Agousa IMA, El-Nashar DE, Eissa SS, Sharoud MN. Possible ameliorative effect of antioxidant (Taurine) in pregnant toxemic female Rats. Open Hypertens J 2009;2:1-15.

19. Kim K, Kim SH, Kim J, Kim H, Yim J. Glutathione s-transferase omega 1 activity is sufficient to suppress neurodegeneration in a Drosophila model of Parkinson disease. J Biol Chem 2012;287:6628-41.

20. Subashini R. Cardioprotective efficacy of nelumbo nucifera leaf extract on a glycoprotein, membrane bound ATPase and lysosomal enzymes against isoproterenol induced cardiotoxicity in wistar rats. Int J Pharm Pharm Sci 2014;6:537-41.

21. Schumann G, Klauke R. New IFCC reference procedures for the determination of catalytic activity concentrations of five enzymes in serum: preliminary upper reference limits obtained in hospitalized subjects. Clin Chim Acta 2003;327:69-79.

22. Young DS. Effects of drugs on clinical laboratory tests. 4 th ed. AACC Press Washington; 1995.

23. Okinaka S, Kumagai H, Ebashi S, Sugita H, Momoi H. Serum creatine phosphokinase. Activity in progressive muscular dystrophy and neuromuscular diseases. Arch Neurol 1961;4:520-5.

24. Young D. Effects of drugs on clinical laboratory tests. Ann Clin Biochem 1997;34:579.

25. Bucolo G, David H. Quantitative determination of serum triglycerides by the use of enzymes. Clin Chem 1973;19:476-82.

26. Allain CC, Poon LS, Chan CS, Richmond W, Fu PC. Enzymatic determination of total serum cholesterol. Clin Chem 1974;20:470-5.

27. Connerty HF, Briggs AR, Eaton EH. Simplified determination of the lipid components of blood serum. Clin Chem 1961;7:37-53.

28. Boden G, Sargrad K, Homko C, Mozzoli M, Stein TP. Effect of a low-carbohydrate diet on appetite, blood glucose levels, and insulin resistance in obese patients with type 2 diabetes. Ann Intern Med 2005;142:403-11.

29. Friedewald WT, Levy RI, Fredrickson DS. Estimation of the concentration of low-density lipoprotein cholesterol in plasma, without the use of the preparative ultracentrifuge. Clin Chem 1972;18:499-502.

30. Kamstrup PR, Benn M, Tybjaerg-Hansen A, Nordestgaard BG. Extreme lipoprotein (a) levels and risk of myocardial infarction in the general population the Copenhagen city heart study. Circulation 2008;117:176-84.

31. Guido S., Joseph T. Effect of chemically different calcium antagonists on lipid profile in rats fed on a high-fat diet. Indian J Exp Biol 1992;30:292-4.

32. Bhaskar I, Rao SB. New, a simple and cheap alternative to troponin test for diagnosis of acute myocardial infarction. Indian J Exp Biol 2002;40:628-30.

33. Kothari HV, Miller BF, Kritchevsky D. Aortic cholesterol esterase: characteristics of normal rat and rabbit enzyme. Biochim Biophys Acta 1973;296:446-54.

34. Hitz J, Steinmetz J, Siest G. Plasma lecithin: cholesterol acyltransferase-reference values and effects of xenobiotics. Clin Chim Acta 1983;133:85-96.

35. Salter AM, White DA. Effects of dietary fat on cholesterol metabolism: regulation of plasma LDL concentrations. Nutr Res Rev 1996; 9:241-57.

36. Swann AC, Steketee JD. Subacute noradrenergic agonist infusions in vivo increase $\mathrm{Na}+\mathrm{K}+-\mathrm{ATPase}$, and ouabain binding in rat cerebral cortex. J Neurochem 1989;52:1598-604.

37. Ohnishi T, Suzuki T, Suzuki Y, Ozawa K. A comparative study of plasma membrane Mg2+-ATPase activities in normal, regenerating and malignant cells. Biochim Biophys Acta 1982;684:67-74.

38. Preuss HG, Jarrell ST, Scheckenbach R, Lieberman S, Anderson RA. Comparative effects of chromium, vanadium, and Gymnema Sylvestre on sugar-induced blood pressure elevations in SHR. J Am Coll Nutr 1998;17:116-23.
39. Marklund S, Marklund G. Involvement of the superoxide anion radical in the autoxidation of pyrogallol and a convenient assay for superoxide dismutase. Eur J Biochem 1974;47:469-74.

40. Kar M, Mishra D. Catalase, peroxidase, and polyphenol oxidase activities during rice leaf senescence. Plant Physiol 1976;57:315-9.

41. Devika PT, Prince PSM. Preventive effect of (-) epigallocatechin gallate on lipids, lipoproteins, and enzymes of lipid metabolism in isoproterenol-induced myocardial infarction in rats. J Biochem Mol Toxicol 2009;23:387-93.

42. Mohanty I, Arya DS, Dinda A, Talwar KK, Joshi S. Mechanisms of cardioprotective effect of Withania somnifera in experimentally induced myocardial infarction. Basic Clin Pharmacol Toxicol 2004;94:184-90.

43. Czubryt MP. Common threads in cardiac fibrosis, infarct scar formation, and wound healing. Fibrog Tissue Repair 2012;5:19.

44. Ziaee M, Khorrami A, Ebrahimi M, Nourafcan H, Amiraslanzadeh M. Cardioprotective effects of essential oil of lavandula angustifolia on isoproterenol-induced acute myocardial infarction in rat. Iranian J Pharm Res 2015;14:279-89.

45. Brooks WW, Conrad CH. Isoproterenol-induced myocardial injury and diastolic dysfunction in mice: structural and functional correlates. Compens Med 2009;59:339.

46. Lombardini JB. Taurine depletion in the intact animal stimulates in vitro phosphorylation of a 44-kDa protein present in the mitochondrial fraction of the rat heart. J Mol Cell Cardiol 1996;28:1957-61.

47. Kim, SJ, RC Gupta, HW Lee. Taurine-diabetes interaction: from involvement to protection. Curr Diabetes Rev 2007;3:165-75.

48. Warskulat U, Flögel U, Jacoby C, Hartwig HG, Thewissen M. Taurine transporter knockout depletes muscle taurine levels and results in severe skeletal muscle impairment but leaves cardiac function uncompromised. FASEB J 2004; 18:577-9.

49. Ohta H, Azuma J, Awata N, Hamaguchi T, Tanaka Y. Mechanism of the protective action of taurine against isoprenaline-induced myocardial damage. Cardiovasc Res 1988;22:407-13.

50. Shi Y, Qi YF, Bu DF, Gao L, Wang DY. Dysfunction of myocardial and vascular taurine transport in spontaneously hypertensive rats. Shengli Xuebao 2002;54:359-64.

51. Aidi W, Yang Z, Lu M, Jianmin H, Yaochuan L. Role of antioxidant activity of taurine in diabetes. Mod J Animal Husbandry Vet Med 2011;4:34.

52. Meng D, Feng L, Chen XJ, Yang D, Zhang JN. Trimetazidine improved $\mathrm{Ca} 2$ +handling in isoprenaline mediated myocardial injury of rats. Exp Physiol 2006;91:591-601.

53. Ramatulla M, Devi KL. Origination and development of isoproterenol-induced myocardial infarction in male wastar rats. Int Res J Pharm 2013;4:26-35.

54. Sudha M, Rajkumar D, Felix JW. Protective effect of glutathione against isoproterenol-induced myocardial injury in rats. Indian J Physiol Pharmacol 2013;57:132-7.

55. Upaganlawar A, Gandhi H, Balaraman R. Isoproterenol-induced myocardial infarction: protective role of natural products. J Pharmacol Toxicol 2011;6:1-17.

56. Schaffer S, Fau-Azuma JTK, Azuma J. Role of osmoregulation in the actions of taurine. J Physiol Sci 2000;16:17-20.

57. Davuluri G, Seiler C, Abrams J, Soriano AJ, Pack M. Differential effects of thin and thick filament disruption on zebrafish smooth muscle regulatory proteins: Zebrafish smooth muscle regulatory proteins. Neurogastroenterol Motil 2010;22:1100-e285.

58. Schaffer S, Ramila KC, Jong CJ, Ito T, Azuma J. Role of protein phosphorylation in TauTKO cardiomyopathy [abstract]. Int Taurine Symp; 2009.

59. Rapundalo ST. Cardiac protein phosphorylation: functional and pathophysiological correlates. Cardiovasc Res 1998;38:559-88.

60. Park Y, Kanekal S, Kehrer JP. Oxidative changes in hypoxic rat heart tissue. Am J Physiol 1991;260:H1395-405.

61. Jia LG, Donnet C, Bogaev RC, Blatt RJ, McKinney CE. Hypertrophy increased ejection fraction and reduced $\mathrm{Na}-\mathrm{K}$ ATPase activity in phospholemman-deficient mice. Am J Physiol: Heart Circ Physiol 2005;288:H1982-8.

62. Ripps H, Shen W. Review: taurine: a "very essential" amino acid. Mol Vision 2012;18:2673-86.

63. Nigam $P$, Narain V, Hasan M. Serum lipid profile in patients with acute myocardial infarction. Indian J Clin Biochem 2004;19:67-70. 
64. Farvin KS, Anandan R, Kumar SH, Shiny KS, Mathew S. Cardioprotective effect of squalene on lipid profile in isoprenalineinduced myocardial infarction in rats. J Med Food 2006;9:531-6.

65. Asha K, Anandan R, Nair P. Effect of fish protein on isoprenaline-induced alterations in lipid and antioxidant status in adipose tissue of rats. Indian J fischaries 2008;45:63-72.

66. Vijayakumar M, Selvi V, Krishnakumari S. Efficacy of Lagenaria siceraria (MOL) on Lipid profile in isoproterenol-induced mycardial infarction in wistar rats. Int J Pharma Bio Sci 2010;1:295-300.

67. Deepa P, Varalakshmi P. Beneficial cardio-renovascular effects of a low-molecular-weight heparin-derivative on adriamycininduced glycosaminoglycan -uria and tissue lipid abnormalities. Toxicology 2005;211:77-85.

68. Yogeeta SK, Hanumantra RB, Gnanapragasam A, Senthilkumar S, Subhashini R. Attenuation of abnormalities in the lipid metabolism during experimental myocardial infarction induced by isoproterenol in rats: beneficial effect of ferulic acid and ascorbic acid. Basic Clin Pharmacol Toxicol 2006;98:467-72.

69. Wei B, You MG, Ling JJ, Wei LL, Wang K. Regulation of the antioxidant system, lipids, and fatty acid $\beta$-oxidation contributes to the cardioprotective effect of sodium tanshinone IIA sulphonate in isoproterenol-induced myocardial infarction in rats. Atherosclerosis 2013;230:148-56.

70. Rashba-Step J, Tatoyan A, Duncan R, Ann D, Pushpa-Rehka TR. Phospholipid peroxidation induces cytosolic phospholipase A 2 activity: membrane effects versus enzyme phosphorylation. Arch Biochem Biophys 1997;343:44-54.

71. Upaganlawar A, Balaraman R. Combined effect of green tea extract and vitamin e on serum and heart tissue lipids, lipid metabolizing enzymes and histopathological alteration in isoproterenol-induced myocardial infarction in rats. Sci Pharm 2009;77:791-803.

72. Radhika J, Surya S, Jothi G, Japasheba JL. The cardioprotective role of justicia traquebareinsis Linn. Leaf extract in isoproterenol induced myocardial infarction in albino rats. J Appl Pharm Sci 2013;3:124-8.

73. Lodish H, Berk A, Zipursky SL, Matsudaira P, Baltimore D. Biomembranes and the subcellular organization of eukaryotic cells. In: Molecular Cell Biology. 4th edn. New York: WH. Freeman; 2000.

74. Al-Yahya MA, Mothana RA, Al-Said MS, El-Tahir KA, AlSohaibani M. Citrus medica "Otroj": attenuates oxidative stress and cardiac dysrhythmia in isoproterenol-induced cardiomyopathy in rats. Nutrients 2013;5:4269-83.

75. Pereira T. Dyslipidemia and cardiovascular risk: lipid ratios as risk factors for cardiovascular disease. INTECH Open Access Publisher; 2012.
76. Militante JD, Lombardini JB. Dietary taurine supplementation: hypolipidemic and antiatherogenic effects. Nutr Res 2004;24:787-801.

77. Du H, You JS, Zhao X, Park JY, Kim SH. Antiobesity and hypolipidemic effects of lotus leaf hot water extract with taurine supplementation in rats fed a high-fat diet. J Biomed Sci 2010;17:S42.

78. Saleh AAS. Effects of taurine and/or ginseng and their mixture on lipid profile and some parameters indicative of myocardial status in streptozotocin-diabetic rats. J Basic Appl Zool 2012;65:267-73.

79. Huxtable R. Physiological actions of taurine. Physiol Rev 1992;72:101-63.

80. Murakami S, Kondo Y, Sakurai T, Kitajima H, Nagate T. Taurine suppresses the development of atherosclerosis in Watanabe heritable hyperlipidemic (WHHL) rabbits. Atherosclerosis 2002;163:79-87.

81. Eilertsen KE, Larsen R, HaMæhre HK, Jensen IJ, Elvevoll EO. Anticholesterolemic and antiatherogenic effects of taurine supplementation is model dependent. In: "Lipoproteins-Role in Health and Diseases," book edited by Sasa Frank and Gerhard Kostner, InTechOpen; 2012.

82. Murakami S, Kondo Y, Sakurai T, Kitajima H, Nagate T. Taurine suppresses the development of atherosclerosis in Watanabe heritable hyperlipidemic (WHHL) rabbits. Atherosclerosis 2002;163:79-87.

83. Heibashy M. Effect of vanadium and taurine on lipid profile and some parameters indicative of myocardial status in male rats with streptozotocin-induced diabetes. J Egypt Ger Soc Zoology 2005;47:117-38.

84. Chen W, Guo JK, Chang P. The effect of taurine on cholesterol metabolism. Mol Nutr Food Res 2012;56:681-90.

85. Chen W, Matuda K, Nishimura N, Yokogoshi H. The effect of taurine on cholesterol degradation in mice fed a high cholesterol diet. Life Sci 2004;74:1889-98.

86. Magnusson AL, Waterman IJ, Wennergren M, Jansson T, Powell TL. Triglyceride hydrolase activities and expression of fatty acid binding proteins in the human placenta in pregnancies complicated by intrauterine growth restriction and diabetes. J Clin Endocrinol Metab 2004;89:4607-14

\section{How to cite this article}

- $\quad$ Eman Salah Abdel-Reheim. Cardioprotective efficacy of taurine on lipid metabolism of isoproterenol-induced myocardial infarction. Int J Pharm Pharm Sci 2016;8(12):135-141. 